\title{
Type_2 Fuzzy Logic Controller System of Maximum Power Point Tracking (MPPT)
}

\author{
${ }^{1}$ Ammar H. Mutlag, ${ }^{2}$ Safaa A. Gadban and ${ }^{2}$ Rasha Kh. Kareem \\ ${ }^{1}$ Department of Computer Engineering Technique, \\ ${ }^{2}$ Department of Electrical Power Engineering Technique, Electrical Engineering Technical College, \\ Middle Technical University, Baghdad, Iraq
}

\begin{abstract}
The most important point in the control of (PV) systems is the design of the maximum power point tracking algorithm. Generally, MPPT depends on the solar irradiance $(\mathrm{G})$ and Temperature (T). Many algorithms are developed for the MPPT to extract the maximum power and improve the efficiency of PV system it can be classified into groups, conventional methods, soft computing methods and evolutionary method. In this study, we proposed a new algorithm for MPPT of a photovoltaic system is Type_2 Fuzzy Logic Control system (T2FLC) to improve the MPPT performance. The T2FLC which can handle with rule uncertainties the application of this T2FLC, involves operations of fuzzification, inference and output processing. A T2FLC simulated using the MATLAB/Simulink package. The results show that the T2FLC algorithm based MPPT fulfil faster and best performance compared with the T1FLC algorithm and the conventional $\mathrm{P} \& \mathrm{O}$ algorithm.
\end{abstract}

Key words: Interval Type_2 Fuzzy Logic (IT2FL), MPPT, PV, the Type_2 Fuzzy Logic Controller (T2FLC), algorithm, performance

\section{INTRODUCTION}

In our world today, the problems caused by global warming and pollution. The effect becomes the important issues for research. Renewable energy sources are considered as a technological option for generating clean energy and environmentally friendly. Many types of renewable energy sources have been mentioned in the literature such as wind turbine, fuel cell and photovoltaic systems (Erdinc and Uzunoglu, 2012). Among them, Photovoltaic (PV) system has received a great attention as it appears to be one of the most promising renewable energy sources and it is considered as the core of Renewable Energy (RE) because it is available almost everywhere unlike wind, geothermal, sea waves, etc. photovoltaic system simply make electricity out of sunlight with no pollution and no depletion of materials.

In addition to the advantage of photovoltaic there is a drawback of photovoltaic generation also has some weaknesses related to controllability and availability. PV generation system needs additional control to maintain desired characteristics such as power, voltage and frequency levels. Another drawback of PV generation system is the power variable depended on the weather condition. These disadvantages have challenged researchers to develop new methods to overcome the problems (Singh, 2013).
Photovoltaic (PV) power generation is a reliable and economical source of electricity that can be utilized in rural areas. The energy conversion efficiency of a PV generation system is low because the solar cell exhibits nonlinear current versus Voltage (I-V) and Power versus Voltage (P-V) characteristics (Tsai et al., 2008). These nonlinear characteristics are a function of weather conditions such as irradiance and temperature (MPPT) mechanism is needed in order to maintain efficient operation. There is a unique point on the Voltage-Power curves (P-V), known as the Maximum Power Point (MPP), in which at this point the photovoltaic is said to operate at maximum efficiency and produces its maximum output power (Graditi et al., 2014). MPPT is the important part in $\mathrm{PV}$ energy system in order to maintain the PV module operating point at its MPP. There are many challenges in the development of MPPT algorithms which include fast-changing weather condition, efficiency and accuracy at steady-state value (Chen et al., 2015). The success of a PV system is highly dependent on the design and performance of its controller. The main problems in the photovoltaic system are low efficiency, intermittent power generation under varying weather condition and the amount of generated power from a photovoltaic depends on the nonlinear current-Voltage (I-V) and Power-Voltage $(\mathrm{P}-\mathrm{V})$ characteristics which vary with irradiance and temperature.

Corresponding Author: Ammar H. Mutlag, Department of Computer Engineering Technique, 
The maximum power when voltage or current is at the MPP of each characteristic curve. However, the MPP also changes with irradiation level and temperature due to the nonlinear characteristic of the PV module (Bhandari et al., 2014). To overcome these problems, many MPPT methods were proposed to obtain maximum power from PV system, so as improve efficiency. The MPPT can be achieved using many methods. These methods can be classified into two types, conventional MPPT approaches and soft computing-based MPPT approaches.

The conventional methods are Perturb and Observe (P\&O), Incremental Conductance (IC) and Hill Climbing (HC) (Esram and Chapman, 2007). The most commonly used MPPT algorithm is $\mathrm{P} \& \mathrm{O}$ method. Is a popular MPPT method used to observe the change power in the system, $\mathrm{P} \& O$ depends on the applied step size for the current/voltage reference (Radjai et al., 2014). In $\mathrm{P} \& \mathrm{O}$ method, we use only one sensor, hence, it is easy to implement. The PV current and voltage at sampling time ( $t$ ) at first measured and then the PV power, $p(t)$ is calculated and compared with previous sample $\mathrm{p}(\mathrm{t}-1)$. If $\mathrm{p}(\mathrm{t})-\mathrm{p}(\mathrm{t}-1)>0$ that mean that the algorithm move toward the Maximum Power Point (MPP). If $\mathrm{p}(\mathrm{t})-\mathrm{p}(\mathrm{t}-1)<0$ that mean that the algorithm is moving away from the Maximum Power Point (MPP) However, P\&O suffer from oscillation occur around the MPP. Another method is HC this method consists to climb the operating point along the generator characteristic to a maximum. It is based on the relationship between the power panel and the value of duty ratio applied to the static converter. The $\mathrm{HC}$ technique is like $\mathrm{P} \& \mathrm{O}$ method. The difference between them is that the $\mathrm{HC}$ method updates the operating point for the PV system by perturbing the duty cycle, instead of the current/voltage. If the instant power is greater than the previously computing power, the direction of perturbation is maintained. Otherwise, it should be reversed (Park et al., 2010). HC method fails under rapidly changing of weather conditions. To overcome the drawback of $\mathrm{P} \& \mathrm{O}$ and $\mathrm{HC}$ method, IC was proposed. The thought behind the IC operation is to determine the MPP by tracking the PV power against the voltage curve (Babu et al., 2015). The IC can find that the MPPT has reached the MPP and stop perturbing the operating point. If this condition is not met, the direction in which the MPPT operating point must be perturbed can be calculated using the relationship between $\mathrm{dl} / \mathrm{dV}$ and $\mathrm{I} / \mathrm{V}$ This relationship is derived from the fact that $\mathrm{dP} / \mathrm{dV}$ is negative when the MPPT is to the right of the MPP and positive when it is to the left of the MPP. This algorithm has advantages over $\mathrm{P} \& \mathrm{O}$ in that it can determine when the MPPT has reached the MPP where $\mathrm{P} \& \mathrm{O}$ oscillates around the MPP. In addition, incremental conductance can track rapidly increasing and decreasing irradiance conditions with higher accuracy than $\mathrm{P} \& O$. The soft computing methods are Fuzzy Logic Control (FLC), Artificial Neural Network (ANN) and other Computational Intelligence (CI).

The main components of (FLC) are fuzzification, rules, and defuzzification. The input variables to fuzzy logic are the change in power of PV module and direction of change in duty cycle of the boost converter. Whereas the output of the FLC is the change of the duty cycle that must be applied to control boost converter. Fuzzy logic MPPT method does not need the knowledge about the model of the system. Therefore, the performance of FLC depends on the rule basis, a number of rules and membership function (Kjaer, 2012). Another soft computing method is ANN in ANN methods, large amounts of field data according to weather conditions are required to train the ANN. While the common idea of the ANN-based PV Model is either by using the instance irradiation and environment temperature as an input and the well-trained reference maximum voltage as the output (Kharb et al., 2014). Another soft computing method is based on $\mathrm{CI}$ method which can be divided into two groups: Swarm intelligence Algorithms (SAs) and Evolutionary Algorithms (EAs). The most common of SAs is Particle Swarm Optimization (PSO). Inspired of the behaviours of nature bird flocking under an environment with little knowledge to search for food, particle swarm optimization is a computational intelligence method that optimizes a problem by emulating a flock searching over candidate solutions (information carried by the particles) through search space (Kaliamoorthy et al., 2010). This algorithm allows all the random particles to search for the optimum solution in the search space through an iterative process. Each particle will learn their best experience while interacting with each other to share their knowledge. The most popular of EAs is a Genetic Algorithm (GA) Genetic Algorithms (GA) are stochastic optimization based on mechanisms of natural selection and genetics. Its operation is extremely simple. It starts with an initial population which is encoded for the model of the problem by some method.

Recently, a new soft computing approach known as a Type-2 Fuzzy Logic Control system (T2FLC) type-2 fuzzy sets and systems generalize standard type-1 fuzzy sets and systems, so that, more uncertainty can be handled. From the very beginning of fuzzy sets, criticism was made about the fact that the membership function of a type-1 fuzzy set has no uncertainty associated with it, something that seems to contradict the word fuzzy since that word has the connotation of lots of uncertainty. So, what does one do when there is uncertainty about the value of the 


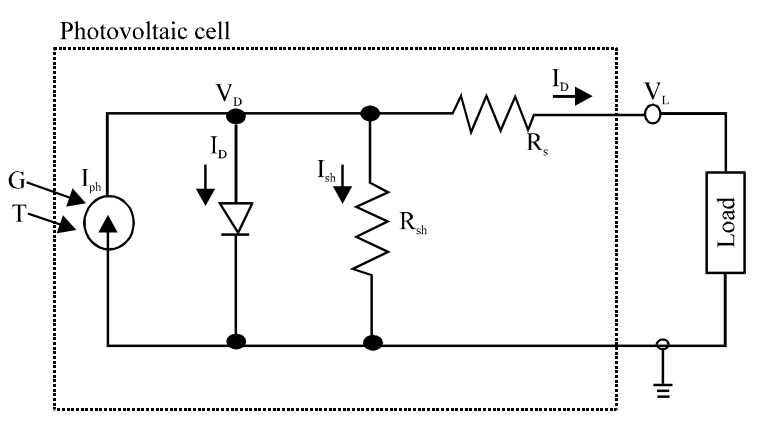

Fig. 1: Electrical equivalent circuit of a solar cell

membership function. The inventor of fuzzy sets, Zadeh (1975) and Veerachary et al. (2003), provided the answer to this question in 1975 when he proposed more sophisticated kinds of fuzzy sets, the first of which he called a type- 2 fuzzy set. A type- 2 fuzzy set lets us incorporate uncertainty about the membership function into fuzzy set theory and is a way to address the above criticism of type-1 fuzzy sets head-on. In addition, if there is no uncertainty, then a type-2 fuzzy set reduces to a type-1 fuzzy set which is analogous to probability reducing to determinism when unpredictability vanishes.

In order to symbolically distinguish between a type-1 fuzzy set and a type-2 fuzzy set, a tilde symbol is put over the symbol for the fuzzy set, so, A denotes a type-1 fuzzy set whereas A denotes the comparable type-2 fuzzy set. When the latter is done, the resulting type-2 fuzzy set is called a general type-2 fuzzy set (to distinguish it from the special interval type-2 fuzzy set.

This study attempts to design and implement the (T2FLC) method to track MPP accurately for the photovoltaic system by considering the problems of the fast-changing for weather conditions. The system is modelled in the MATLAB/Simulation to elucidate the performance of the proposed controller (Fig. 1).

\section{MATERIALS AND METHODS}

Modelling and characteristic of PV system: The equivalent electrical circuit for a solar cell consists of a current source, series resistor $\mathrm{Rs}$, parallel-connected resistor, $\mathrm{R}_{\mathrm{sh}}$ and a diode shown in Fig. 1. The mathematical model of the circuit which represents the output of the cell current (I) is expressed as (Saravana and Babu, 2016):

Where:

$$
I=I_{p h}-I_{0}\left(e^{\left(\frac{\left(\mathrm{q}\left(\mathrm{V}+1^{*} \mathrm{R}_{\mathrm{s}}\right)\right.}{\mathrm{n} \cdot \mathrm{k} \cdot \mathrm{T}}\right)}-1\right)-\frac{\mathrm{v}+\mathrm{I}^{*} \mathrm{R}_{\mathrm{s}}}{\mathrm{R}_{\mathrm{sh}}}
$$

$\mathrm{I} \quad=\mathrm{A}$ PV cell current $(\mathrm{A})$

I_PV $=$ A Photocurrent $(\mathrm{A})$

$\mathrm{I}_{0} \quad=$ A Cell reverse saturation current $(\mathrm{A})$ $\mathrm{q}=$ An electronic charge $\left(1.6^{*} 10-19 \mathrm{C}\right)$

$\mathrm{V}=\mathrm{A}$ cell output Voltage $(\mathrm{V})$

$\mathrm{R}$ _sis $=$ A series resistance $(\Omega)$

$\mathrm{n}=$ An ideality factor

$\mathrm{k}=$ A Boltzmann's constant $\left(1.38^{*} 10-23 \mathrm{~J} / \mathrm{k}\right)$

$\mathrm{T}=\mathrm{A}$ cell temperature $(\mathrm{k})$ and $\mathrm{R}$ _shis a shunt resistance $(\Omega)$

The light-generated current extracted from the PV cell, I_ (PV) is directly proportional to the PV irradiance $(\mathrm{G})$ and Temperature $(\mathrm{T})$. Assuming the nominal condition for $(\mathrm{G})$ and $(\mathrm{T})$ denoted by $(\mathrm{Gn})$ and $(\mathrm{T}$ n), I_PVat other conditions can be calculated as Eq. 2:

$$
I_{p h}=\left[I_{s c}, n+\alpha\left(T-T_{n}\right)\right] \frac{G}{G_{n}}
$$

where, $\mathrm{I}_{\mathrm{sc}}, \mathrm{n}$ is short-circuit current at the nominal condition and $\alpha$ is short-circuit current temperature coefficient which are provided by the manufactures datasheet as shown in Table 1. The solar cell reverses saturation current, Io as shown in Eq. 3, depends only on the Temperature, $\mathrm{T}$ and it is not related to the light condition. Io in open circuit voltage can be calculated using (Zadeh, 1975):

$$
I_{0}=\frac{I_{S C}, n+\alpha\left(T-T_{n}\right)}{e\left(\frac{q}{n k \cdot T} V O C, n+\beta\left(T-T_{n}\right)\right)-1}
$$

where, $V_{o c} n$ is open-circuit at nominal condition and $\beta$ is open-circuit voltage temperature coefficient which are in the manufacture's datasheet as shown in Table 1 .

Proposed Type_2 Fuzzy Logic Control system (T2FLC) MPPT approach: On the contrary, most algorithms of MPPT, like $\mathrm{IC}, \mathrm{HC}$ and $\mathrm{P} \& \mathrm{O}, \mathrm{G}$ and $\mathrm{T}$ are utilized in the proposed method as inputs they can be integrated in more than one way in modern $\mathrm{PV}$ system. If you consider $\mathrm{T}$ and $\mathrm{G}$ are available as input, then (T2FLC) soft computing approach is proposed to process the inputs to get the wanted reference current $\llbracket \mathrm{I} \rrbracket$ MPP to the PV controller as we see in Fig. 2. Therefore, this study is looking for improvement of (T2FLC) based MPPT algorithm utilizing old data for G and T and I_(MPP) values we get from the model described by Eq. 1 .

Overview of the type_2 fuzzy logic control system: Sometimes type 1 fuzzy logic is uncertain in rule-based. So, we utilized the type_ 2 fuzzy logic system to minimize the effects of uncertainties in rules (Gonzalez-Longatt, 2005). In the type_1fuzzy logic system, there are four sources of uncertainties rules antecedents and consequents of rules can be uncertain the meaning of 
Table 1: Photovoltaic module characteristics

\begin{tabular}{ll}
\hline PV module type: $M X-150 \mathrm{M}$ & Values \\
\hline Rated $_{\max }$ Power $\left(\mathrm{P}_{\max }\right)$ & $150 \mathrm{~W}$ \\
Voltage at $\left(\mathrm{P}_{\max }\right)\left(\mathrm{V}_{\mathrm{MP}}\right)$ & $18.1 \mathrm{~V}$ \\
Current at $\mathrm{P}_{\max }\left(\mathrm{I}_{\mathrm{MP}}\right)$ & $8.31 \mathrm{~A}$ \\
Open-circuit Voltage $\left(\mathrm{V}_{\mathrm{oc}}\right)$ & $22.4 \mathrm{~V}$ \\
Short-circuit current $\left(\mathrm{I}_{\mathrm{sc}}\right)$ & $8.66 \mathrm{~A}$ \\
Current temperature coefficient $(\alpha)$ & $0.06 \mathrm{~A} / \mathrm{C}$ \\
Voltage temperature coefficient $(\beta)$ & $-0.47 \mathrm{~V} / \mathrm{C}$ \\
\hline
\end{tabular}

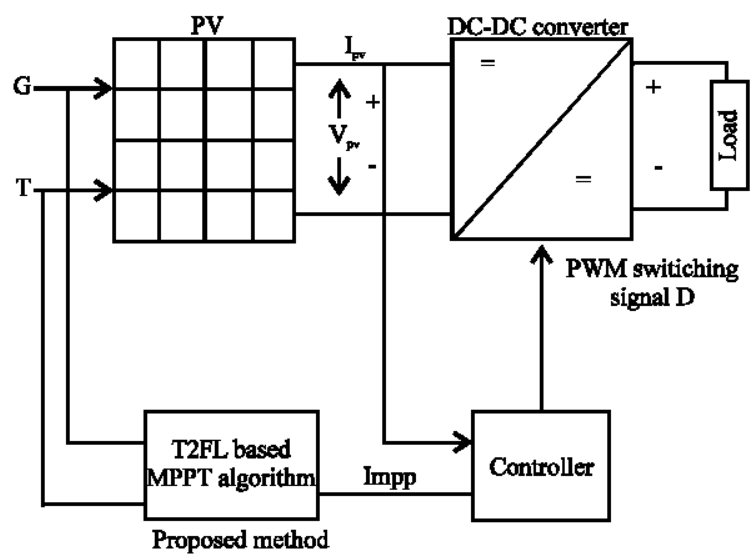

Fig. 2: T2FLC based MPPT algorithm for controlling PV output power

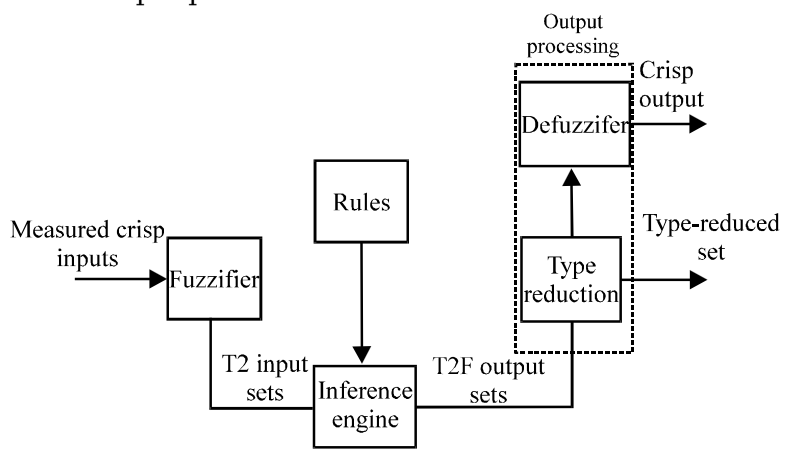

Fig. 3: Type_2 fuzzy logic controller system

words which are utilized in the antecedents and consequents of rules may be uncertain (words mean different things to different people). Consequents can have a histogram of values that connected with them especially when knowledge is extracted by a group of experts who do not agree. Mmeasurements which activate a type_1 FLS can be noisy thus uncertain. The data, which are utilized to tune, the parameters of a type_1 FLS may also be noisy.

Because of the membership functions are totally crisp, so, type 1 fuzzy sets are not able to directly model such uncertainties. In type_1 fuzzy sets, the membership functions are two-dimensional whereas type_2 fuzzy sets the membership functions are three-dimensional. The new third dimension in type_2 provides additional degrees of freedom that make it possible to directly model uncertainties. A type-2 FLC is shown in Fig. 3. It includes five components: fuzzifier, rules, inference engine, type reducer and defuzzifier. In a T2 FLC, the inputs or outputs are represented by $\mathrm{T} 2 \mathrm{FSs}$ and it works as follows: crisp inputs, obtained from input sensors are fuzzified into input $\mathrm{T} 2$.

Fss which then activate an inference engine that uses the same rules used in a T1 FLC for produce output T2 FSs. These are then processed by a type reducer that projects the T2 FSs into a T1 FS (this step is called type reduction) (De Soto et al., 2006) after which that T1 FS is defuzzified to produce a crisp output that for example can be utilized as the command to an actuator in the control system. Type reduction followed by defuzzification is usually indicated to as output processing. Interval Type_2 Fuzzy Logic Controller system (IT2FLS) was proposed to simpler the mathematical complexity of (T2FLS). The IT2FLS uncertainty designation into the third dimension where the value of $\mathrm{MF}$ is also a dimensional domain. This IT2FLS is a simpler form of T2FLS and depending on the mathematics of T1FLS (Mendel, 2001). The main difference is that the defuzzified block of a T1FLS is replaced by an output processing block in a T2FLS. This block is the formation of a type reduction followed by defuzzification, meaning the type reduction the task that maps a T2FS to a T1FS. This can be mapping the uncertainty to an (IFT2) between the upper membership function and the lower membership function.

\section{RESULTS AND DISCUSSION}

The performance and response of the MPPT to track MPP for the $150 \mathrm{~W}$ photovoltaic system have been simulated by utilizing MATLAB/Simulink. The response of the proposed T2FLC algorithm is compared with the soft computing T1FLC algorithm and with the conventional $\mathrm{P} \& \mathrm{O}$ algorithm to display its capability to track the MPP under the nominal condition for PV modules as shown in Fig. 4. The figure shows the T2FLC algorithm can track the $150 \mathrm{~W}$ power and fulfil very fast response compared with the T1FLC algorithm and with the $\mathrm{P} \& \mathrm{O}$ algorithm. The proposed T2FLC algorithm compared to the T1FLC algorithm and with a P\&O algorithm can significantly improve the speed response of MPPT. The demeanour of the MPPT based on the T2FLC algorithm is also characterized by a stable and oscillation-free power around the MPP at the same time, the demeanour of the MPPT by the T1FLC algorithm and $\mathrm{P} \& \mathrm{O}$ algorithm have large oscillation around the MPP as shown in Fig. 5. 


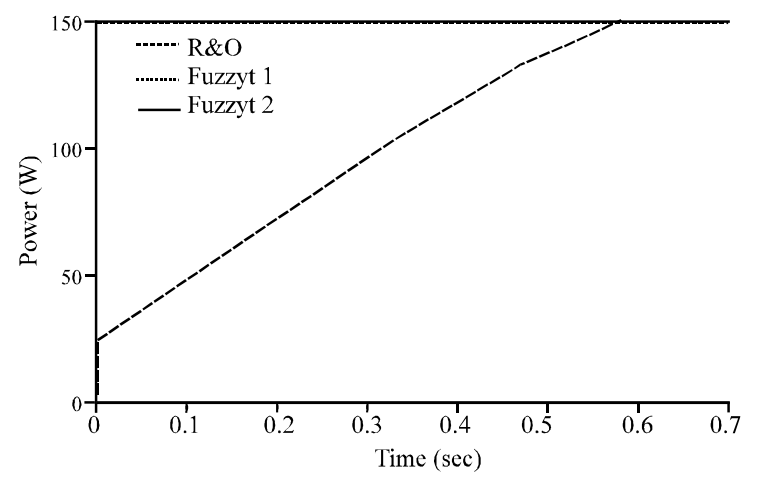

Fig. 4: Seed response of the T2FLC with T1FLC and P\&O

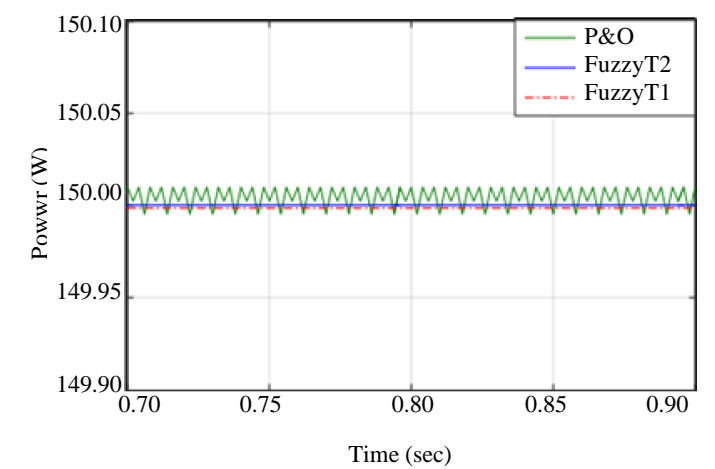

Fig. 5: Steady-state responses of the T2FLC with T1FLC and $\mathrm{P} \& \mathrm{O}$

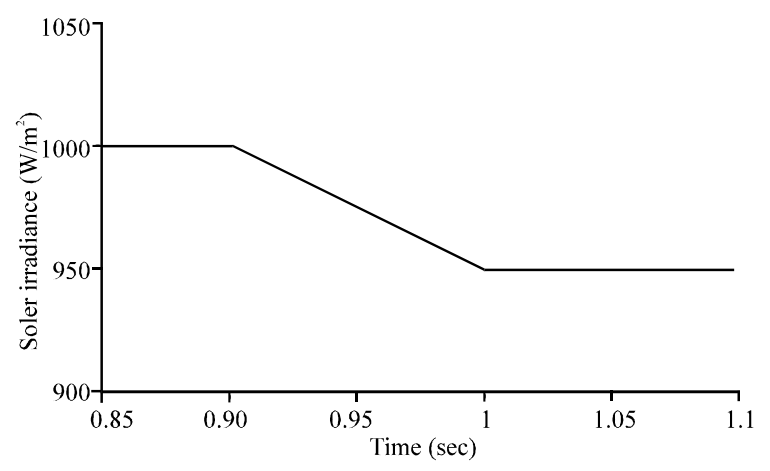

Fig. 6: Ramp irradiance change

For further evaluation, simulations were executed out under various solar irradiances $(G)$ with constant Temperature $(\mathrm{T})$ where the irradiance is changed with a ramp from $1000-950 \mathrm{~W} / \mathrm{m}^{2}$ as shown in Fig. 6. The response to this case the ramp irradiance change as shown in Fig. 7. It shows that the proposed T2FLC algorithm can extract more power compared with the T1FLC algorithm and with the conventional $\mathrm{P} \& \mathrm{O}$ algorithm. In addition, the T2FLC algorithm carried out faster response with small oscillation meanwhile the T1FLC algorithm and conventional $\mathrm{P} \& \mathrm{O}$ algorithm shows

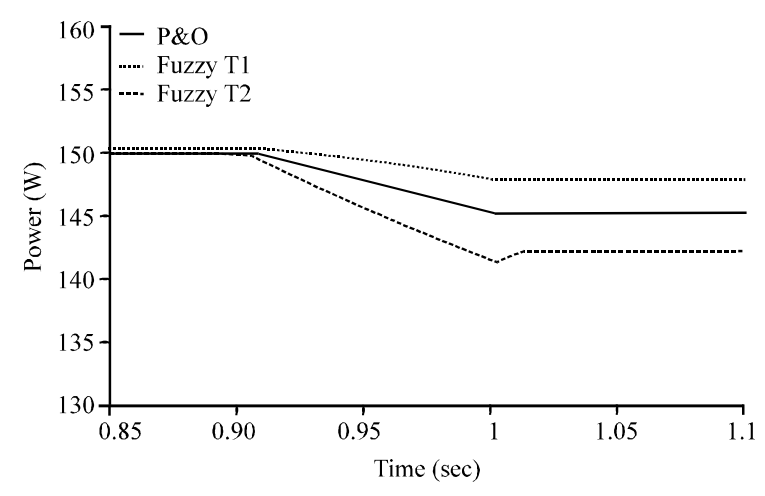

Fig. 7: Response of T2FLC withT1FLC and P\&O for the ramp irradiance change

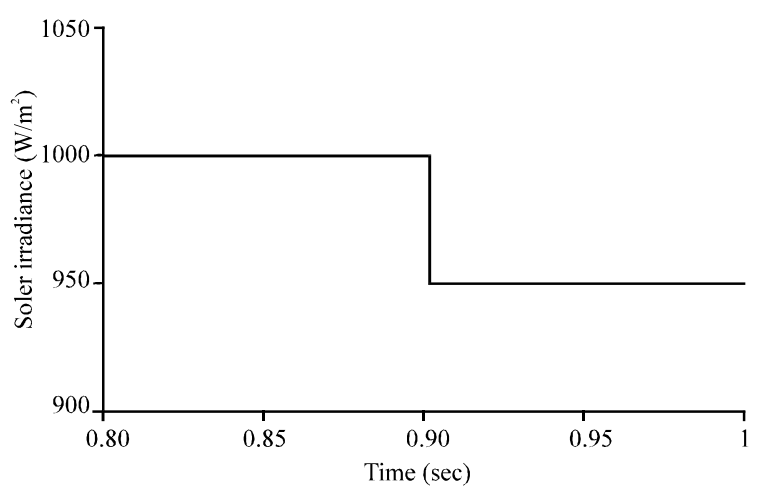

Fig. 8: Step irradiance change

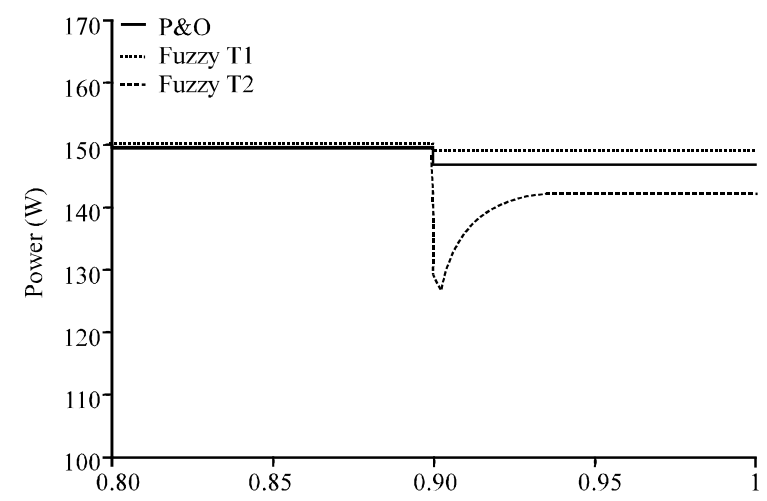

Fig. 9: Response of T2FLC with T1FLC and $\mathrm{P} \& \mathrm{O}$ for the step irradiance change

a large oscillation during the ramp irradiance change. For further valuation, the step irradiance change is also implemented. A step change of $\mathrm{G}$ from $1000-950 \mathrm{~W} / \mathrm{m}^{2}$ as shown in Fig. 8 was simulated. Figure 9 shows the response of the step $\mathrm{G}$ change, it can be seen that the proposed T2FLC algorithm can fulfil very fast response and track the MPP with very short time compared with 


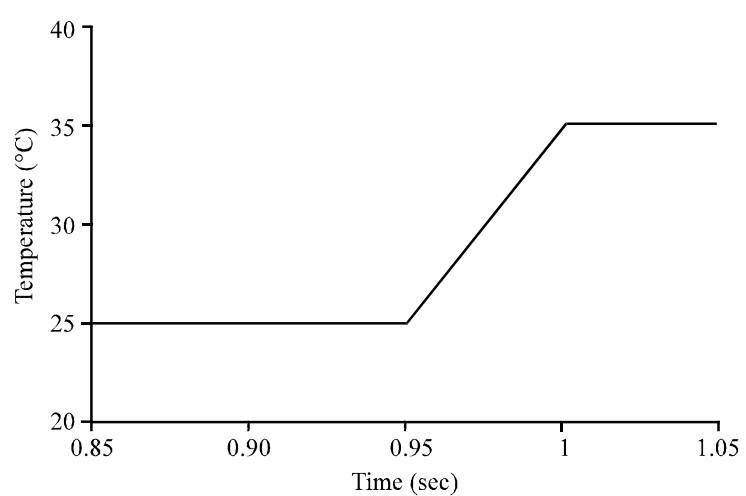

Fig. 10: Ramp temperature change

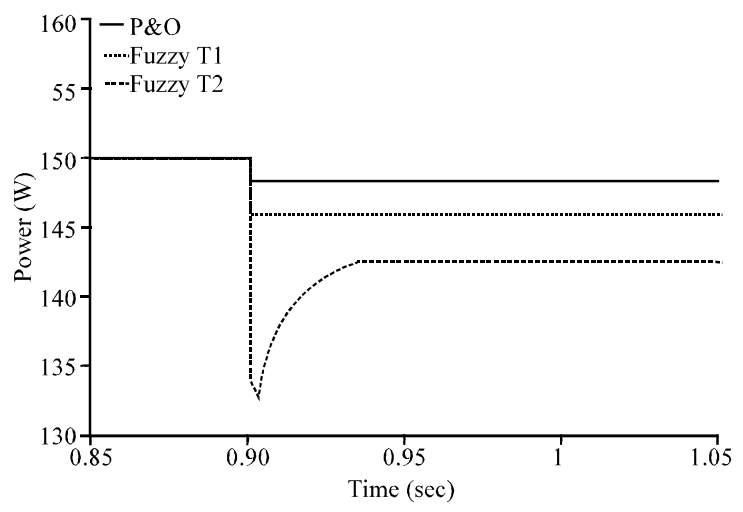

Fig. 11: Response of T2FLC with T1FLC and P\&O

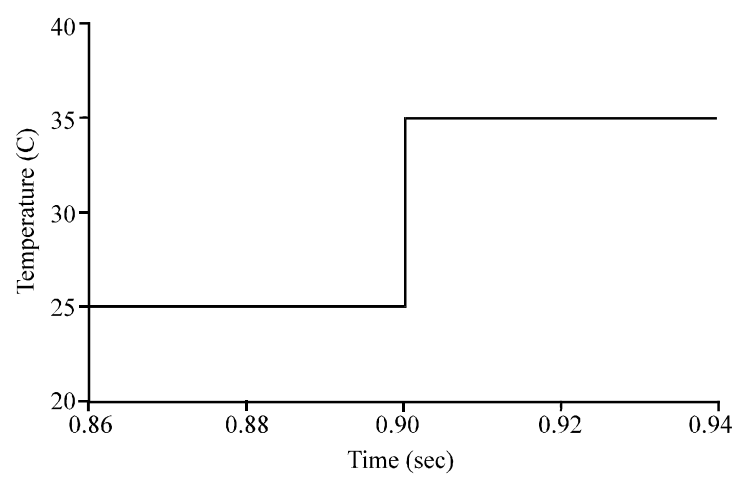

Fig. 12: Step temperature change

the T1FLC algorithm and $\mathrm{P} \& \mathrm{O}$ algorithm. In addition, the proposed T2FLC algorithm fulfil the MPP with very small oscillation different the T1FLC algorithm and P\&O algorithm as shown in Fig. 8. Another valuation is made by carrying out simulations under various Temperatures (T) with constant irradiance $(\mathrm{G})$ where the temperature ramps from 25-35 as shown in Fig. 10. Figure 11 show the response of the proposed T2FLC with T1FLC and $\mathrm{P} \& \mathrm{O}$. The extracted power from the T2FLC algorithm is major

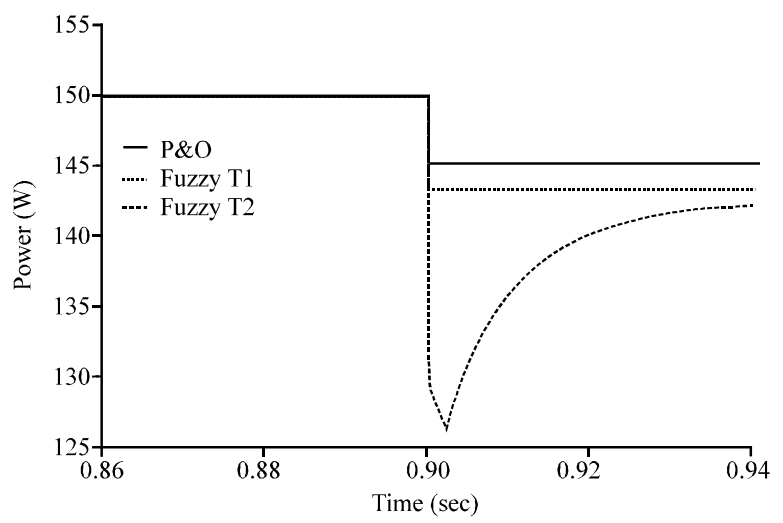

Fig. 13: Response of T2FLC with T1FLC and $\mathrm{P} \& \mathrm{O}$ for the step temperature change

compared with extracted power from the T1FLC algorithm and $\mathrm{P} \& \mathrm{O}$ algorithm with much faster response time as can be seen in Fig. 11. Another test case is simulated with a step (T) change as shown in Fig. 12 from 25-35 and the identical response is shown in Fig. 13. The response indicates that the T2FLC algorithm achieves the best performance compared with the T1FLC algorithm and $\mathrm{P} \& \mathrm{O}$ algorithm.

\section{CONCLUSION}

This study inserts a new MPPT algorithm based on T2FLC for $150 \mathrm{~W}$ PV system was developed in MATLAB/Simulink to simulate various conditions and change in PV irradiance and temperature. Simulation result indicates that the proposed T2FLC algorithm in all various condition can be achieved best performance compared with the T1FLC algorithm and conventional $\mathrm{P} \& \mathrm{O}$ algorithm. The T2FLC algorithm achieves to track the MPP in all test conditions. Moreover, the result clearly showed that the proposed T2FLC algorithm is robust compared with the T1FLC algorithm and the conventional $\mathrm{P} \& \mathrm{O}$ algorithm.

\section{REFERENCES}

Babu, T.S., N. Rajasekar and K. Sangeetha, 2015. Modified particle swarm optimization technique based maximum power point tracking for uniform and under partial shading condition. Appl. Soft Comput., 34: 613-624.

Bhandari, B., S.R. Poudel, K.T. Lee and S.H. Ahn, 2014. Mathematical modeling of hybrid renewable energy system: A review on small hydro-solar-wind power generation. Intl. J. Precis. Eng. Manuf. Green Technol., 1: 157-173. 
Chen, P.C., P.Y. Chen, Y.H. Liu, J.H. Chen and Y.F. Luo, 2015. A comparative study on maximum power point tracking techniques for photovoltaic generation systems operating under fast changing environments. Sol. Energy, 119: 261-276.

De Soto, W., S.A. Klein and W.A. Beckman, 2006. Improvement and validation of a model for photovoltaic array performance. Solar Energy, 80: 78-88.

Erdinc, O. and M. Uzunoglu, 2012. Optimum design of hybrid renewable energy systems: Overview of different approaches. Renewable Sustainable Energy Rev. Elsevier, 16: 1412-1425.

Esram, T. and P.L. Chapman, 2007. Comparison of photovoltaic array maximum power point tracking techniques. IEEE Trans. Energy Convers., 22: 439-449.

Gonzalez-Longatt, F.M., 2005. Model of photovoltaic module in Matlab. II. Cibelec, 2005: 1-5.

Graditi, G., G. Adinolfi and G.M. Tina, 2014. Photovoltaic optimizer boost converters: Temperature influence and electro-thermal design. Appl. Energy, 115: 140-150.

Kaliamoorthy, M., R.M. Sekar and I.G.C. Raj, 2010. Solar powered single stage boost inverter with ANN based MPPT algorithm. Proceedings of the 2010 International Conference on Communication Control and Computing Technologies, October 7-9, 2010, IEEE, Ramanathapuram, India, ISBN:978-1-4244-7769-2, pp: 165-170.

Kharb, R.K., S.L. Shimi, S. Chatterji and M.F. Ansari, 2014. Modeling of solar PV module and maximum power point tracking using ANFIS. Renewable Sustainable Energy Rev., 33: 602-612.

Kjaer, S.B., 2012. Evaluation of the hill climbing and the incremental conductance maximum power point trackers for photovoltaic power systems. IEEE. Trans. Energy Conversion, 27: 922-929.
Mendel, J.M., 2001. Uncertain Rule-Based Fuzzy Logic Systems: Introduction and new Directions. Prentice Hall, Upper Saddle River, New Jersey, ISBN:9780130409690, Pages: 555.

Park, S.H., G.R. Cha, Y.C. Jung and C.Y. Won, 2010. Design and application for PV generation system using a soft switching boost converter with SARC. IEEE. Trans. Ind. Electron., 57: 515-522.

Radjai, T., L. Rahmani, S. Mekhilef and J.P. Gaubert, 2014. Implementation of a modified incremental conductance MPPT algorithm with direct control based on a fuzzy duty cycle change estimator using dSPACE. Sol. Energy, 110: 325-337.

Saravanan, S. and N.R. Babu, 2016. Maximum power point tracking algorithms for photovoltaic system-A review. Renew. Sustain. Energy Rev., 57: 192-204.

Singh, G.K., 2013. Solar power generation by PV (photovoltaic) technology: A February 12, 2019review. Energy, 53: 1-13.

Tsai, H.L., C.S. Tu and Y.J. Su, 2008. Development of generalized photovoltaic model using MATLAB/SIMULINK. Proceedings of the World Congress on Engineering and Computer Science, October 22-24, 2008, San Francisco, USA., pp: 1-6.

Veerachary, M., T. Senjyu and K. Uezato, 2003. Neural-network-based maximum-power-point tracking of coupled-inductor interleaved-boost-convertersupplied PV system using fuzzy controller. IEEE. Trans. Ind. Electron., 50: 749-758.

Zadeh, L.A., 1975. The concept of a linguistic variable and its application to approximate reasoning-I. Inform. Sci., 8: 199-249. 